ciones propias del autor. Los ejercicios se acompañan generalmente de ilustraciones, pero a veces las descripciones no son adecuadas y alguien no familiarizado con el sistema no aprenderá los ejercicios correctamente. Las notas 3 a 9 del capítulo 8 se han perdido [en la edición en castellano sólo se numeran dos notas].

Los capítulos finales narran las prácticas y experiencias del autor con varios profesores, con un particular énfasis en Sam Tam. El autor acredita que Tam alcanza un nivel de maestría que incluye la habilidad del uso de la "nofuerza", que es lo mismo que decir que Tam es capaz de controlar a un oponente sólo con la conciencia.

Puesto que las artes marciales y de la salud internas cada vez se refieren más a la práctica de la meditación en pie, es importante poder explorar las técnicas y los documentos que constituyen su cimentación. Este libro realiza una respetable contribución a este aspecto vital del entrenamiento de las artes marciales.

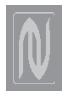

\section{European Internal Arts Journal}

Editores: Ronnie Robinson y

Helmut Oberlack

Hamburgo: Internal Arts Media, (2004-)

135-155 páginas. $27 \times 19 \mathrm{~cm}$.

Ilustraciones

Semestral • $10 € /$ ejemplar

Idioma: Francés e Inglés

Disponible en:

Internal Arts Media

Klopstockstr. 11

D-22765 Hamburg (Alemania)

Telf.: +49(0) $40-85372200$

Fax: $+49(0) 40-85372201$

E-mail: mail@internalartsjournal.com http://www.internalartsjournal.com/

\section{Revisión por Carlos Gutiérrez García}

El European Internal Arts Journal es una publicación periódica bilingüe (francés/inglés) de carácter semestral centrada en la divulgación de estudios, entrevistas, revisiones y otros aspectos relativos a las denominadas "artes internas” en Europa (Taijiquan, Yiquan, Baguazhang, Xingyiquan, etc.). Se trata de una iniciativa emprendida por dos profundos conocedores de estas disciplinas, el escocés Ronnie Robinson -editor de la revista Tai Chi Chuan $\mathcal{E}$ Internal Arts y Secretario de la Federación Europea de Taijiquan y Qigong- y el alemán Helmut Oberlack -editor del Taijiquan 8 Qigong Journal y Vice-Presidente de la federación antecitada-. El primer número del EIAJ se publicaba en octubre de 2004 y el segundo en julio de 2005, existiendo en la actualidad -mayo de 2006- un retraso de varios meses en la edición del tercer número de la revista.

Cada número del EIAJ se estructura en varias secciones: editorial, corresponsales, socios colaboradores, cartas, noticias, artículos, acontecimientos, revisiones, directorio, agenda de talleres y seminarios, avance del próximo número y anuncios publicitarios. El EIAJ combina, por tanto, contenidos que profundizan en su ámbito de conociendo, bajo la forma de artículos, junto con información de actualidad relativa a noticias, acontecimientos, talleres, etc.

Por lo que respecta a los artículos, estos componen cuantitativamente la parte principal de la revista. Los autores de los mismos son personas con un amplio currículum marcial que se resume someramente en cada contribución. Priman los autores europeos sobre los de otros continentes, en consonancia con el ámbito europeo que define el título de la revista. En este sentido, el EIAJ es un claro reflejo de las pulsiones de asimilación y/o transformación que experimentan las artes marciales en su evolución temporal y en su adaptación a contextos culturales diferentes a los que las vieron gestarse. Así, podemos encontrar trabajos centrados en el desarrollo de conceptos y teorías netamente orientales junto con otros estudios que abordan las transformaciones de las artes marciales internas en Occidente. Entre los primeros pueden citarse "Qigong as a Portal to Presence", por Gunther Weill, "Baguazhang - a bystander's primer to the art of change", por Daniel Skyle, o "Daoying Yangsheng Gong”, por Martin Pendzialek, y entre los segundos "Internal Arts as a Competitive Sport", por Torben Rif, o "Internal Arts - A European Perspective", por Anya Meot. Las personas interesadas en conocer todos los artículos publicados hasta el momento en los dos números de la revista pueden consultarlos en su la página web (www. internalartsjournal.com).

La perspectiva de los artículos no es, por lo general, estrictamente académica, aunque sí lo suficientemente seria como para considerar positivamente la calidad de esta publicación. Las entrevistas están bien seleccionadas y focalizadas, no perdiéndose en anécdotas o detalles poco relevantes. Acompañan a ambos tipos de trabajos un buen número de ilustraciones, algunas de las cuales pueden destacarse por su valor histórico o estético.

En lo que se refiere a la información de actualidad, resulta especialmente interesante el calendario de diversos tipos de encuentros (congresos, foros, cursos, campeonatos, etc.) relativos a las artes marciales internas. Dichos encuentros, que se celebran en numerosos países europeos, muestran la creciente vitalidad de estas disciplinas y son también un buen referente para cualquier persona interesada en aumentar su dominio y comprensión de dichas artes. Por cuanto, como hemos dicho, se anuncia una notable variedad de eventos, es fácil que el lector encuentre algunos que estén en consonancia con su forma de practicar y entender las artes marciales. Otro aspecto interesante es la publicidad de diversas escuelas, equipos de entrenamiento y publicaciones ligadas a las artes marciales internas.

Para el lector europeo, en definitiva, el EIAJ puede ser una publicación periódica de referencia para conocer el estado de las artes marciales internas en el continente, y por ello sería deseable que la revista estabilizase su periodicidad. Especialmente para los profesores y/o profesionales de este campo, constituye un importante elemento de actualización en unas disciplinas en las que aún hoy queda mucho por explorar y que además tienen un gran potencial de desarrollo debido al interés que despiertan en amplios sectores sociales.

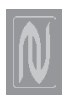

